\title{
Commentary
}

\section{Immersion and the illusion of presence in virtual reality}

\author{
Mel Slater ${ }^{1,2 *}$ (D) \\ 'Event Lab, Faculty of Psychology, University of Barcelona, Spain \\ ${ }^{2}$ Department of Computer Science, University College London, UK
}

This commentary briefly reviews the history of virtual reality and its use for psychology research, and clarifies the concepts of immersion and the illusion of presence.

Virtual reality (VR) appears to be making a 'comeback', and Pan and Hamilton (2018) have usefully brought it to the attention of the psychology community, concentrating mainly on social psychology. It is worth noting first that VR has been around in something like its present form since the late 1980s. Readers may be surprised to learn that some of the VR systems at that time, systems that were actually sold, were highly sophisticated and multiperson (more than one person could simultaneously share the same virtual environment seeing avatar representations of each other), with full stereo display, head tracking, and at least hand tracking - for example (Blanchard et al., 1990). For a wonderful review of the early days of VR, see Lanier (2017). What has changed since that time is accessibility and of course a massive increase in graphics and computing power. A system today with a quite high-quality wide field-of-view stereo head-mounted display, with six degrees of freedom head tracking, and even hands and feet tracking, can cost a few hundred euros, and the computer needed to drive it is a PC or Mac with an up-to-date graphics card (even a higher end laptop will be good enough). A similar capability, say, 7 years ago cost tens of thousands of euros. The last head-mounted display we bought in my laboratory before the advent of the first Oculus cost \$35000. Additionally, the headtracking set-up cost around $\$ 15000$ and we also bought two full-body tracking systems one for $\$ 20000$ and the other for $\$ 50000$. In the early 1990s, such a system would have cost more in the order of hundreds of thousands, and around half of this cost would have been a computer specialized for graphics. Today, research that we do in the laboratory can be applied, in principle, in the office and the home. Hence, as a methodology for experimental studies in psychology, it is now highly feasible to consider VR as an option. (Of course, these costs do not take account salaries of the programmers needed to create the scenarios).

The classic reference for the use of VR in social psychology is Blascovich et al. (2002). With more than 720 citations (according to Google Scholar), and with already 20 in 2018 at the time of writing, it has stood the test of time. It covers similar ground to the current paper and also includes a theoretical model of social influence in VR.

*Correspondence should be addressed to Mel Slater, Event Lab, Universitat de Barcelona, Campus de Mundet - Edifici Teatre, Passeig de la Vall d'Hebron I 7I, 08035 Barcelona, Spain (email: melslater@ub.edu). 
Since that paper, which came out of a highly productive psychology group at the University of California Santa Barbara led by Prof. Jack Loomis, who had written a preceding paper on the use of VR in psychology (Loomis, Blascovich, \& Beall, 1999), there have been numerous studies that have exploited VR to address issues in social psychology. For example, Pan and Hamilton (2018) discuss a recent proxemics study (McCall \& Singer, 2015), research that has a long history, for example (Bailenson, Blascovich, Beall, \& Loomis, 2003).

The definition by Pan and Hamilton (2018) of VR as simply 'a computer-generated world' may be at once both too simplistic and too all embracing. The fundamental element of any VR system must include a computer-generated world of course but ideally one that perceptually surrounds the participant, and where perception is a function at least of head tracking. Nevertheless, so-called desktop VR might still be considered as VR. But rather than a binary definition, in Slater (2009) I defined 'immersion' as an objective property of a system, and higher or lower immersion as the extent to which a VR system can support natural sensorimotor contingencies for perception (O'Regan \& Noë, 2001) including the response to a perceptual action (hence aspects such as display resolution and stereo are intrinsically connected to perception). So a system that supported being able to perceive using the whole body (bending down to look underneath something, reaching out, looking around an object, etc.) would be at a higher level of immersion than one that just afforded looking at a screen (for as soon as you turn your head away from the screen you are no longer perceiving the virtual world). In this way, systems can be classified by the extent to which one system can be used to simulate another. In principle, a higher level immersive system, such as a wide field-ofview, high-resolution, stereo, head-tracked head-mounted display with full real-time motion capture, and auditory and haptic feedback could be used to simulate the experience of a desktop VR system and therefore would be considered at a higher level of immersion. Then, based on this type of classification (which is a partial order), researchers can study how different levels of immersion might correspond to different levels of the illusion of being in the virtual world (the place illusion component of presence), and the extent to which people respond as if events in the virtual world were really happening. This approach also supports psychophysics based measures of presence that do not require questionnaires (Slater, Spanlang, \& Corominas, 2010).

On the subject of presence, the authors in their section the 'challenge of presence' use the word 'belief' - that it seems impossible that people would believe the virtual world to be the real thing. However, presence is not about belief. Of course no one, not even when they are standing by a virtual precipice with their heart racing and feeling great anxiety, ever believes in the reality of what they are perceiving. The whole point of presence is that it is the illusion of being there, notwithstanding that you know for sure that you are not. It is a perceptual but not a cognitive illusion, where the perceptual system, for example, identifies a threat (the precipice) and the brain-body system automatically and rapidly reacts (this is the safe thing to do), while the cognitive system relatively slowly catches up and concludes 'But I know that this isn't real'. But by then it is too late, the reactions have already occurred.

This is the real power of VR, and, like any illusion, even though you know it is an illusion, this does not change your perception or your response to it. When you look at a Necker cube you know for sure that it is only an arrangement of 12 lines on a flat surface, but you cannot help seeing it as a cube. In VR, we know that the precipice is not there, or in the Virtual Milgram Obedience experiment, participants knew for sure that nothing real was happening, but they still tended to respond as if they were causing harm to the virtual 
Learner - in spite of the very simple rendering of the character representing the Learner (since presence is not even about realism).

Virtual reality did not suddenly appear out of nowhere in 2012. It has a long history, with massive amounts of research in the past 30 years (Slater \& Sanchez-Vives, 2016), not least in different areas of psychology. This timely article by Pan and Hamilton (2018) brings VR to the attention of a wide audience, and hopefully, the next 30 years will be even more productive than the last, given the widespread availability now of immersive systems.

\section{Acknowledgement}

This commentary is based on the research under the ERC Advanced Grant MoTIVE (\#742989).

\section{References}

Bailenson, J. N., Blascovich, J., Beall, A. C., \& Loomis, J. (2003). Interpersonal Distance in Immersive Virtual Environments. Personality and Social Psychology Bulletin, 29, 1-15. https://doi.org/ $10.1177 / 0146167203029007002$

Blanchard, C., Burgess, S., Harvill, Y., Lanier, J., Lasko, A., Oberman, M., \& Teitel, M. (1990). Reality built for two: A virtual reality tool. ACM SIGGRAPH Computer Graphics, 24(2), 35-36. https:// doi.org/10.1145/91385.91409

Blascovich, J., Loomis, J., Beall, A. C., Swinth, K., Hoyt, C., \& Bailenson, J. N. (2002). Immersive Virtual Environment Technology as a methodological tool for Social Psychology. Psychology Inquiry, 13, 103-124. https://doi.org/10.1207/S15327965PLI1302_01

Lanier, J. (2017). Dawn of the new everything: A journey through virtual reality. London, UK: Bodley Head.

Loomis, J. M., Blascovich, J. J., \& Beall, A. C. (1999). Immersive virtual environment technology as a basic research tool in psychology. Behavior Research Methods Instruments and Computers, 31, 557-564. https://doi.org/10.3758/BF03200735

McCall, C., \& Singer, T. (2015). Facing off with unfair others: Introducing proxemic imaging as an implicit measure of approach and avoidance during social interaction. PLOS ONE, 1O(2), e0117532. https://doi.org/10.1371/journal.pone.0117532

O'Regan, J. K., \& Noë, A. (2001). What it is like to see: A sensorimotor theory of perceptual experience. Synthese, 129, 79-103. https://doi.org/10.1023/A:101269922

Pan, X., \& Hamilton, A. F. D. C. (2018). Why and how to use virtual reality to study human social interaction: The challenges of exploring a new research landscape. British Journal of Psychology. 109(3), 1-23. https://doi.org/10.1111/bjop.12290

Slater, M. (2009). Place Illusion and Plausibility can lead to realistic behaviour in immersive virtual environments. Philosophical Transactions of the Royal Society of London, 364, 3549-3557. https://doi.org/10.3389/frobt.2016.00074

Slater, M., \& Sanchez-Vives, M. V. (2016). Enhancing Our Lives with Immersive Virtual Reality. Frontiers in Robotics and AI, 3, 74. https://doi.org/10.3389/frobt.2016.00074

Slater, M., Spanlang, B., \& Corominas, D. (2010). Simulating virtual environments within virtual environments as the basis for a psychophysics of presence. ACM Transactions on Graphics, 29, Paper 92. https://doi.org/10.1145/1833349.1778829

Received 15 March 2018 